\title{
Exploration of the Effect of Tobacco Smoking on Metabolic Measures in Young People Living with HIV
}

\author{
Mark L. Rubinstein, ${ }^{1}$ D. Robert Harris, ${ }^{2}$ Bret J. Rudy, ${ }^{3}$ \\ Bill G. Kapogiannis, ${ }^{4}$ Grace M. Aldrovandi, ${ }^{5}$ and Kathleen Mulligan ${ }^{1,6}$ \\ ${ }^{1}$ University of California, San Francisco, San Francisco, CA 94117, USA \\ ${ }^{2}$ Westat, Rockville, MD 20850, USA \\ ${ }^{3}$ New York University School of Medicine, New York, NY 10016, USA \\ ${ }^{4}$ Maternal and Pediatric Infectious Diseases Branch, Eunice Kennedy Shriver National Institute of Child Health \\ and Human Development, NIH, Bethesda, MD 20892, USA \\ ${ }^{5}$ Children's Hospital Los Angeles, University of Southern California, Los Angeles, CA 90027, USA \\ ${ }^{6}$ San Francisco General Hospital Division of Endocrinology, Building 30, Room 3501K, 1001 Potrero Avenue, \\ San Francisco, CA 94110, USA
}

Correspondence should be addressed to Kathleen Mulligan; kathleen.mulligan@ucsf.edu

Received 18 March 2014; Revised 30 May 2014; Accepted 8 June 2014; Published 9 July 2014

Academic Editor: Robert R. Redfield

Copyright ( 2014 Mark L. Rubinstein et al. This is an open access article distributed under the Creative Commons Attribution License, which permits unrestricted use, distribution, and reproduction in any medium, provided the original work is properly cited.

\begin{abstract}
We conducted cross-sectional, multicenter studies in HIV-positive young women and men to assess metabolic and morphologic complications from tobacco smoking in 372 behaviorally infected HIV-positive youth, aged 14-25 years. Measurements included self-reported tobacco use, fasting lipids, glucose, fat distribution, and bone mineral density (BMD; dual-energy X-ray absorptiometry scans). Overall, 144 (38.7\%) self-reported smoking tobacco and 69 (47.9\%) of these reported smoking greater than five cigarettes per day. Smokers versus nonsmokers had lower mean total cholesterol (146.0 versus $156.1 \mathrm{mg} / \mathrm{dL} ; P<0.01)$ and lower mean total body fat percent $(24.1 \%$ versus $27.2 \%, P=0.03)$. There was no difference between smokers and nonsmokers in fasting glucose or BMD. There appear to be only minimal effects from tobacco smoking on markers of cardiac risk and bone health in this population of HIV-positive youth. While these smokers may not have had sufficient exposure to tobacco to detect changes in the outcome measures, given the long-term risks associated with smoking and HIV, it is critical that we encourage HIV-positive youth smokers to quit before the deleterious effects become apparent.
\end{abstract}

\section{Introduction}

Tobacco smoking is still the number one cause of preventable mortality in the United States (US) [1]. Unfortunately, the prevalence of smoking among people living with HIV/AIDS (PLWHA) is much greater than among the general population. In fact, it is estimated that $45 \%$ to $74 \%$ of adult PLWHA smoke [2-5], compared with $21 \%$ of the general population of US adults [6]. Furthermore, as PLWHA live longer, the morbidity and mortality associated with HIV infection has shifted towards heart disease and cancer, both of which are dramatically increased with tobacco smoking $[7,8]$. Tobacco smoking is the most important modifiable lifestyle factor contributing to cardiovascular disease among HIV-positive patients [9].

One of the factors associated with the increase in cardiovascular risk among smokers is increased dyslipidemia $[10,11]$. Tobacco smoking is also related to cardiovascular risk through its association with insulin resistance and impaired glucose tolerance $[12,13]$. Of great importance to PLWHA, all of these cardiovascular effects may be further compounded by the fact that some of the medications used to manage HIV, including protease inhibitors, are associated with increased lipid levels and the development of impaired glucose tolerance and insulin resistance [14]. 
In addition to its effects on cardiovascular risk factors [10], tobacco smoking is also associated with increased risk of bone fracture in both HIV-negative [15] and HIV-positive populations [16]. The association between tobacco use and bone mineral density (BMD) is influenced by both dose and duration of smoking [17-20]. In fact, tobacco smoking is a risk factor for osteoporotic fractures, independent of body mass and of BMD [20]. Similar to the cardiovascular risk factors discussed above, HIV and some of the medications used to manage it have also been associated with a reduced BMD [21, 22]; thus smoking may compound these effects.

Although studies in adults provide evidence that smoking is associated with markers of accelerated risk for cardiovascular disease and decreased bone mass, it is uncertain whether these abnormalities are found in adolescents and young adult smokers. More importantly, HIV itself, as well as many of the medications used to treat HIV, is also associated with these same metabolic complications in HIV-infected youth and, as such, the combination of smoking and HIV may be even more damaging. This analysis aims to examine the effects of smoking on the lipid, glucose, and bone density profiles of adolescent and young adult smokers with HIV/AIDS, using merged data collected in two studies of the metabolic effects of HIV infection and its therapies in adolescents and young adults.

\section{Methods}

2.1. Subjects. Studies were conducted at 18 clinical sites on behalf of the Adolescent Medicine Trials Network for HIV/AIDS Interventions (ATN). Separate cross-sectional surveys were conducted in young women (ATN study 021a [23]) and young men (ATN study 021b [22]) to assess metabolic and morphologic complications in behaviorally HIV-positive youth, aged 14-25 years. Eligible youth were recruited consecutively from the clinic populations. All clinical sites were located in urban areas. The data obtained from these two surveys were combined for this analysis. In the original studies, participants were classified on the basis of current antiretroviral therapy (ART) as follows: antiretroviral naïve $(N=190)$; receiving an ART regimen that contained a nonnucleoside reverse transcriptase inhibitor (NNRTI) but no protease inhibitor (PI) for $\geq 3$ months $(N=86)$; receiving an ART regimen that included a PI but no NNRTI for $\geq 3$ months $(N=78)$; or receiving a non-PI/non-NNRTI containing regimen for $\geq 3$ months $(N=18$, all female). Those included in the non-PI groups must have had no more than 6 months exposure to a PI in total and none in the preceding year; those in the non-NNRTI groups must have had no more than 6 months total exposure to an NNRTI and none in the preceding year. All participants had acquired HIV infection through risk behavior, were Tanner stage 4 or 5 , and had accessible medical and medication histories. Exclusion criteria from both studies included type 1 diabetes mellitus and use of androgens or systemic glucocorticoids. Women were required to have a negative pregnancy test at the time of study unless surgically sterilized.
2.2. Informed Consent. The research design and procedures were reviewed and approved by the Institutional Review Boards at each clinical site. Appropriate written informed consent/assent was obtained before enrollment.

2.3. Experimental Procedures. Fasting ( $\geq 8$ hours) blood samples were collected for determination of lipids, glucose, insulin, and high-sensitivity C-reactive protein (hsCRP). Participants then underwent a 2-hour oral glucose tolerance test, with consumption of a 75-gram glucose load and collection of samples for measurement of glucose and insulin. Height and weight were measured following standard protocols. Separate dual-energy X-ray absorptiometry (DXA) scans of the left hip, spine, and whole body were performed with central analysis at Tufts University by readers who were blinded to ART regimen. Machine-generated Z-scores (using sexspecific standard deviations adjusted for race/ethnicity and age) for spine (L1-L4) and hip BMD were used. Z-scores for total body bone mineral content (BMC) were calculated using norms developed at Baylor University [24]. Total and regional fat and lean body mass (LBM) were obtained from the wholebody DXA scans and normalized for height squared.

All participants underwent detailed medical and health histories, including current and previous drug use. Dietary intake, alcohol use, and exercise and smoking habits were assessed using the Block Food Frequency Questionnaire (NutritionQuest, Berkeley, CA). Current tobacco use was queried in the Food Frequency Questionnaire as follows: the participant was first asked "do you smoke cigarettes now"; if the answer was "yes," the questionnaire then asked "on average about how many cigarettes a day do you smoke now," with answers categorized as " $1-5,6-14,15-24,25-34$, and 35 or more."

2.4. Laboratory Analyses. HIV-1 RNA levels (Roche AMPLICOR v1.5 assay) and CD4 T-cell counts were measured locally at each site. All other laboratory samples were batched at the end of each study and analyzed at Quest Diagnostics, Baltimore, MD, and Quest Diagnostics Nichols Institute, Chantilly, VA. Total and high-density lipoprotein (HDL) cholesterol and triglycerides were measured by enzymatic techniques, and low density lipoprotein (LDL) cholesterol was calculated in those with triglyceride levels $<400 \mathrm{mg} / \mathrm{dL}$ [25]. Specimens for glucose determination, which were collected on sodium fluoride/potassium oxalate, were assessed by the hexokinase technique. Serum insulin was measured by immunoassay and hsCRP was measured by a particleenhanced immunonephelometric assay.

2.5. Data Analyses. Data collected from all HIV-positive participants in the parent studies were included in this analysis. The distribution of continuous measures according to smoking status was examined on the basis of means, standard deviations (SD), and medians, with $P$ values provided to assess the significance of the associations with smoking status using Student's two-sample $t$-test. Frequencies and proportions are reported for categorical measures according to smoking status, with $P$ values obtained using Fisher's exact 
TABLE 1: Demographics of HIV-positive youth smokers and nonsmokers.

\begin{tabular}{|c|c|c|c|}
\hline Variable & Smokers $(n=144)$ & Nonsmokers $(n=228)$ & $P$ value $^{1}$ \\
\hline Age in years: mean (SD) & $21.6(2.0)$ & $20.8(2.3)$ & $<0.001$ \\
\hline \multicolumn{4}{|l|}{ Race: $n(\%)$} \\
\hline Black/African American & $89(62.7)$ & $168(74.3)$ & \multirow{3}{*}{0.05} \\
\hline White & $19(13.4)$ & $17(7.5)$ & \\
\hline Other/mixed race & $34(23.9)$ & $41(18.1)$ & \\
\hline Hispanic ethnicity: $n(\%)$ & $38(26.4)$ & $48(21.1)$ & 0.26 \\
\hline Years since HIV-positive diagnosis: mean (SD) & $2.5(2.2)$ & $2.2(2.0)$ & 0.30 \\
\hline Current $\log _{10}$ viral load (copies/mL): mean (SD) & $3.4(1.0)$ & $3.2(1.1)$ & 0.02 \\
\hline Current viral load $\leq 400$ copies/mL: $n(\%)$ & $49(34.5)$ & $109(48.2)$ & 0.01 \\
\hline Current CD4 count (cells $\left./ \mathrm{mm}^{3}\right)$ : mean (SD) & $495(273)$ & $536(319)$ & 0.18 \\
\hline \multicolumn{4}{|l|}{ Current antiretroviral use by drug class: $n(\%)$} \\
\hline ART-naive & $84(58.3)$ & $106(46.5)$ & \multirow{4}{*}{0.17} \\
\hline NNRTI, no PI & $27(18.8)$ & $59(25.9)$ & \\
\hline PI, no NNRTI & $27(18.8)$ & $51(22.4)$ & \\
\hline Non-PI, non-NNRTI ${ }^{2}$ & $6(4.2)$ & $12(5.3)$ & \\
\hline Use alcohol: $n(\%)$ & $123(85.4)$ & $136(59.6)$ & $<0.001$ \\
\hline Use marijuana, hash: $n(\%)$ & $120(83.3)$ & $95(41.7)$ & $<0.001$ \\
\hline Use crack: $n(\%)$ & $6(4.2)$ & $3(1.3)$ & 0.09 \\
\hline Use cocaine: $n(\%)$ & $43(29.9)$ & $18(7.9)$ & $<0.001$ \\
\hline Use methamphetamine: $n(\%)$ & $20(13.9)$ & $10(4.4)$ & 0.002 \\
\hline Exercise regularly: $n(\%)$ & $61(42.4)$ & $98(43.0)$ & 0.91 \\
\hline
\end{tabular}

$\mathrm{SD}=$ standard deviation.

${ }^{1} P$ values obtained from Student's $t$-test for continuous measures and Fisher's exact test for categorical measures.

${ }^{2}$ This antiretroviral drug class was used only in the study of females.

test. In addition to examining associations of smoking status with metabolic and body habitus measures, associations of smoking status with other lifestyle factors, such as use of alcohol and recreational drugs, were explored.

Generalized linear regression modeling was used to examine the association of cigarette smoking with study outcomes, adjusting for covariates selected for inclusion in the model using a stepwise forward selection approach. Candidate covariates, including antiretroviral therapy type, were screened for possible inclusion in the modeling on the basis of their bivariable associations with smoking status, with an alpha level of $\leq 0.10$ used for selection. Covariates whose distributions would pose problems for the modeling due to missing data or small cell sizes in the bivariable analyses were excluded from consideration. Covariates that are traditionally considered for adjustment (i.e., age, sex, race, and height) were included in the modeling regardless of the significance of their bivariable associations with smoking status. HIV-specific candidate covariates included HIV RNA, CD4 measures, CDC disease classification, and the type of ART regimen subjects who were receiving at the time of study enrollment, as well as whether or not their current ART regimen included ritonavir, a PI that has been widely associated with lipid abnormalities [14]. The modeling also considered individual substance use, including use of alcohol, cannabinoids (marijuana or hash), and stimulants (cocaine, crack, amphetamine sulphate, methamphetamine, or other stimulants). The possibility of a dose-response relationship between the average number of cigarettes smoked per day and the study outcomes was also explored in the modeling by separating tobacco users into those who reported smoking $\leq 5$ cigarettes/day and those reporting $>5$ cigarettes/day. Data from one participant who was using a statin were excluded from the modeling analyses.

\section{Results}

In this population of HIV-positive participants, 144 (38.7\%) self-reported smoking tobacco, and 69 (47.9\%) of these reported smoking greater than 5 cigarettes per day (CPD). Demographic and HIV disease-related characteristics of the participants are presented in Table 1 . Reported time since first HIV-positive diagnosis did not differ significantly between smokers and nonsmokers $(P=0.3)$. However, smokers had a significantly higher mean $\log _{10}$ viral load (HIV RNA level), and a smaller proportion of the smokers had HIV RNA $\leq 400$ copies/mL ( $P \leq 0.02$ for both measures). Mean CD4 T lymphocyte counts did not differ significantly between smokers and nonsmokers $(P=0.18)$. There were no significant differences between groups in use of different classes of antiretroviral therapies $(P=0.17)$.

3.1. Lifestyle. Use of alcohol, cannabinoids, cocaine, and methamphetamines was reported significantly more frequently by smokers than nonsmokers $(P \leq 0.002)$. Less 
TABLE 2: Metabolic factors and smoking status among HIV-positive youth.

\begin{tabular}{|c|c|c|c|c|}
\hline Metabolic factor & $\begin{array}{c}\text { Smokers } \\
\text { Mean (SD) } \\
\text { Median }\end{array}$ & $\begin{array}{c}\text { Nonsmokers } \\
\text { Mean (SD) } \\
\text { Median }\end{array}$ & Unadjusted $P$ value $^{1}$ & Adjusted $P$ value ${ }^{2}$ \\
\hline Total cholesterol (mg/dL) & $\begin{array}{c}146.0(29.5) \\
145.5\end{array}$ & $\begin{array}{c}156.1(33.4) \\
153.0\end{array}$ & 0.003 & 0.009 \\
\hline HDL cholesterol (mg/dL) & $\begin{array}{c}61.9(34.7) \\
45.5\end{array}$ & $\begin{array}{c}68.8(35.6) \\
60.5\end{array}$ & 0.07 & 0.09 \\
\hline LDL cholesterol (mg/dL) & $\begin{array}{c}64.1(28.8) \\
60.0\end{array}$ & $\begin{array}{c}66.9(31.6) \\
57.0\end{array}$ & 0.39 & 0.52 \\
\hline Non-HDL cholesterol (mg/dL) & $\begin{array}{c}107.2(27.4) \\
105.0\end{array}$ & $\begin{array}{c}114.0(33.0) \\
110.0\end{array}$ & 0.03 & 0.08 \\
\hline Triglycerides (mg/dL) & $\begin{array}{c}100.0(53.3) \\
90.0\end{array}$ & $\begin{array}{c}98.8(63.3) \\
82.0\end{array}$ & 0.85 & 0.83 \\
\hline Fasting glucose (mg/dL) & $\begin{array}{c}88.5(7.5) \\
88.0\end{array}$ & $\begin{array}{c}88.2(8.1) \\
88.0\end{array}$ & 0.71 & 0.77 \\
\hline 2-hour glucose (mg/dL) & $\begin{array}{c}87.8(26.5) \\
85.0\end{array}$ & $\begin{array}{c}93.0(24.0) \\
92.0\end{array}$ & 0.05 & 0.08 \\
\hline Fasting insulin $(\mu \mathrm{IU} / \mathrm{mL})$ & $\begin{array}{c}9.4(7.4) \\
8.0\end{array}$ & $\begin{array}{c}10.6(11.3) \\
8.0\end{array}$ & 0.23 & 0.31 \\
\hline 2-hour insulin $(\mu \mathrm{IU} / \mathrm{mL})$ & $\begin{array}{c}42.4(46.5) \\
29.0\end{array}$ & $\begin{array}{c}49.6(46.4) \\
39.0\end{array}$ & 0.16 & 0.16 \\
\hline hsCRP (mg/dL) & $\begin{array}{c}3.50(6.52) \\
1.00\end{array}$ & $\begin{array}{c}2.96(5.91) \\
1.00\end{array}$ & 0.41 & 0.40 \\
\hline BMI $\left(\mathrm{kg} / \mathrm{m}^{2}\right)$ & $\begin{array}{c}25.0(6.5) \\
23.5\end{array}$ & $\begin{array}{c}25.8(6.2) \\
24.1\end{array}$ & 0.22 & 0.24 \\
\hline Total body fat percent & $\begin{array}{c}24.1(13.1) \\
20.7\end{array}$ & $\begin{array}{c}27.2(13.2) \\
25.6\end{array}$ & 0.03 & 0.03 \\
\hline Total body fat $\left(\mathrm{kg} / \mathrm{m}^{2}\right)$ & $\begin{array}{c}6.4(5.1) \\
4.5\end{array}$ & $\begin{array}{c}7.3(5.0) \\
5.6\end{array}$ & 0.09 & 0.10 \\
\hline Trunk fat $\left(\mathrm{kg} / \mathrm{m}^{2}\right)$ & $\begin{array}{c}3.0(2.5) \\
2.1\end{array}$ & $\begin{array}{c}3.4(2.5) \\
2.5\end{array}$ & 0.15 & 0.18 \\
\hline Lower extremity (leg) fat $\left(\mathrm{kg} / \mathrm{m}^{2}\right)$ & $\begin{array}{c}2.4(2.1) \\
1.7\end{array}$ & $\begin{array}{c}2.9(2.1) \\
2.4\end{array}$ & 0.04 & 0.04 \\
\hline Total lean body mass $\left(\mathrm{kg} / \mathrm{m}^{2}\right)$ & $\begin{array}{c}17.3(2.5) \\
17.0\end{array}$ & $\begin{array}{c}17.3(2.5) \\
17.1\end{array}$ & 0.83 & 0.83 \\
\hline
\end{tabular}

$\mathrm{SD}=$ standard deviation.

${ }^{1} P$ values obtained from Student's $t$-test.

${ }^{2} P$ values obtained from generalized linear regression modeling; smoking status, race, height, gender, and age at enrollment were included in all of the models, regardless of their significance, while current antiretroviral regimen and current use of marijuana, stimulants, or alcohol were included only if they contributed significantly to the model.

than half of smokers and nonsmokers reported regularly exercising (42.4 versus $43.0 \%$, resp.; $P=0.91$ ).

3.2. Fasting Lipids. Mean total cholesterol was significantly lower among smokers than nonsmokers (146.0 versus $156.1 \mathrm{mg} / \mathrm{dL} ; P=0.003$ ) (Table 2 ). These results remained significant after adjusting for possible confounders $(P=$ 0.009 ). HDL cholesterol tended to be lower in smokers, but the difference did not achieve statistical significance in the unadjusted $(P=0.07)$ or adjusted $(P=0.09)$ analyses. The mean level of LDL cholesterol was similar between smokers and nonsmokers $(P=0.52)$. Mean non-HDL cholesterol levels were also significantly lower in smokers than nonsmokers (107.2 versus $114.0 \mathrm{mg} / \mathrm{dL} ; P=0.03$ ). These results were not significant after adjusting for relevant confounders.
3.3. Fasting Glucose/Insulin. Mean fasting glucose levels were similar between smokers and nonsmokers. The 2-hour glucose was lower in smokers, although only of borderline significance in the adjusted model $(87.8$ versus $93.0 \mathrm{mg} / \mathrm{dL}$; $P=0.08$ ) (Table 2). Similarly, there was no difference in mean fasting insulin or 2-hour insulin levels for smokers compared to nonsmokers $(P>0.1)$.

3.4. Body Composition/Bone Mass. Adjusting for covariates, mean body mass index (BMI) was similar in smokers and nonsmokers (25.0 versus $\left.25.8 \mathrm{~kg} / \mathrm{m}^{2} ; P=0.24\right)$. However, differences in body composition were noted. Mean total body fat percent was significantly lower in smokers $(24.1 \%$ versus $27.2 \% ; P=0.03)$; this difference persisted with adjustment for relevant confounders $(P=0.03)$. Most of this difference appears to be related to lower extremity fat where smokers 
TABLE 3: Association of average number of cigarettes smoked per day (CPD) with metabolic markers among HIV-positive youth.

\begin{tabular}{|c|c|c|c|c|}
\hline Outcome measure & $\begin{array}{c}\leq 5 \mathrm{CPD} \\
\text { Mean }(\mathrm{SD}) \\
\text { Median }\end{array}$ & $\begin{array}{c}>5 \text { CPD } \\
\text { Mean }(\mathrm{SD}) \\
\text { Median }\end{array}$ & $\begin{array}{c}\text { Nonsmokers } \\
\text { Mean (SD) } \\
\text { Median }\end{array}$ & $P$ value $^{1}$ \\
\hline HDL cholesterol (mg/dL) & $\begin{array}{c}60.5(33.9) \\
45.0\end{array}$ & $\begin{array}{c}63.1(35.8) \\
50.0\end{array}$ & $\begin{array}{c}68.7(35.6) \\
60.0\end{array}$ & 0.18 \\
\hline LDL cholesterol (mg/dL) & $\begin{array}{c}65.0(28.1) \\
61.0\end{array}$ & $\begin{array}{c}63.1(29.6) \\
59.0\end{array}$ & $\begin{array}{c}67.0(31.6) \\
57.0\end{array}$ & 0.63 \\
\hline Non-HDL cholesterol (mg/dL) & $\begin{array}{c}105.7(28.6) \\
105.0\end{array}$ & $\begin{array}{c}108.5(26.5) \\
104.0\end{array}$ & $\begin{array}{c}114.0(33.1) \\
110.0\end{array}$ & 0.10 \\
\hline Triglycerides $(\mathrm{mg} / \mathrm{dL})$ & $\begin{array}{c}97.4(50.7) \\
85.0\end{array}$ & $\begin{array}{c}102.5(56.8) \\
92.0\end{array}$ & $\begin{array}{c}98.8(63.5) \\
82.0\end{array}$ & 0.87 \\
\hline Fasting glucose $(\mathrm{mg} / \mathrm{dL})$ & $\begin{array}{c}88.4(8.0) \\
88.0\end{array}$ & $\begin{array}{c}88.9(6.8) \\
88.0\end{array}$ & $\begin{array}{c}88.2(8.1) \\
88.0\end{array}$ & 0.84 \\
\hline 2-hour glucose (mg/dL) & $\begin{array}{c}85.8(26.1) \\
83.5\end{array}$ & $\begin{array}{c}90.3(27.2) \\
87.0\end{array}$ & $\begin{array}{c}93.1(24.0) \\
92.0\end{array}$ & 0.10 \\
\hline Fasting insulin $(\mu \mathrm{IU} / \mathrm{mL})$ & $\begin{array}{c}9.0(6.5) \\
8.0\end{array}$ & $\begin{array}{c}9.8(8.4) \\
8.0\end{array}$ & $\begin{array}{c}10.6(11.3) \\
8.0\end{array}$ & 0.47 \\
\hline 2-hour insulin $(\mu \mathrm{IU} / \mathrm{mL})$ & $\begin{array}{c}46.9(57.0) \\
29.5\end{array}$ & $\begin{array}{c}38.5(33.1) \\
26.0\end{array}$ & $\begin{array}{l}49.8(46.5) \\
39.0\end{array}$ & 0.22 \\
\hline hsCRP (mg/dL) & $\begin{array}{c}2.8(5.9) \\
0.9\end{array}$ & $\begin{array}{c}4.3(7.2) \\
1.5\end{array}$ & $\begin{array}{c}3.0(5.9) \\
1.0\end{array}$ & 0.25 \\
\hline BMI $\left(\mathrm{kg} / \mathrm{m}^{2}\right)$ & $\begin{array}{c}24.6(6.5) \\
22.9\end{array}$ & $\begin{array}{c}25.5(6.6) \\
23.9\end{array}$ & $\begin{array}{c}25.8(6.2) \\
24.1\end{array}$ & 0.37 \\
\hline Total body fat percent & $\begin{array}{c}23.0(12.6)^{*} \\
18.2\end{array}$ & $\begin{array}{c}25.3(13.7) \\
22.8\end{array}$ & $\begin{array}{c}27.2(13.2) \\
25.4\end{array}$ & 0.06 \\
\hline Total body fat $\left(\mathrm{kg} / \mathrm{m}^{2}\right)$ & $\begin{array}{c}6.0(4.7) \\
4.0\end{array}$ & $\begin{array}{c}6.9(5.5) \\
5.3\end{array}$ & $\begin{array}{c}7.3(5.0) \\
5.6\end{array}$ & 0.15 \\
\hline Trunk fat $\left(\mathrm{kg} / \mathrm{m}^{2}\right)$ & $\begin{array}{c}2.7(2.3) \\
1.8\end{array}$ & $\begin{array}{c}3.3(2.7) \\
2.5\end{array}$ & $\begin{array}{c}3.4(2.5) \\
2.5\end{array}$ & 0.13 \\
\hline Lower extremity fat $\left(\mathrm{kg} / \mathrm{m}^{2}\right)$ & $\begin{array}{c}2.4(2.0) \\
1.6\end{array}$ & $\begin{array}{c}2.5(2.3) \\
1.8\end{array}$ & $\begin{array}{c}2.9(2.1) \\
2.4\end{array}$ & 0.12 \\
\hline Total body lean $\left(\mathrm{kg} / \mathrm{m}^{2}\right)$ & $\begin{array}{c}17.3(2.4) \\
17.1\end{array}$ & $\begin{array}{c}17.4(2.7) \\
17.0\end{array}$ & $\begin{array}{c}17.3(2.5) \\
17.1\end{array}$ & 0.93 \\
\hline
\end{tabular}

$\mathrm{SD}=$ standard deviation.

${ }^{1} P$ values obtained from generalized linear regression modeling (GLM).

${ }^{*}$ Significantly different compared to nonsmokers $(P<0.05)$.

had 2.4 compared with $2.9 \mathrm{~kg} / \mathrm{m}^{2}$ in nonsmokers $(P=0.04$ in unadjusted and adjusted analyses). Considering the number of cigarettes smoked per day (Table 3), the difference in mean total body fat percent among smoking categories was only of borderline significance $(P=0.06)$, yet pairwise comparisons indicated that the mean level was significantly lower among those who smoked an average of 5 or fewer cigarettes per day than among nonsmokers $(23.0 \%$ versus $27.2 \% ; P<$ $0.05)$. Lean body mass did not differ between smokers and nonsmokers in either the unadjusted or adjusted analyses (Table 2). There were no differences between smokers and nonsmokers in any measure of BMD or BMC $(P>0.1$, data not shown).

\section{Discussion}

We examined the effects of tobacco smoking on markers of cardiovascular and bone health among a sample of behaviorally infected young HIV-positive smokers and nonsmokers. Although total cholesterol was lower among smokers, much of this difference may have been accounted for by the lowering of HDL cholesterol. In fact, similar to findings in adult tobacco smokers [26, 27], we found a trend toward lower HDL cholesterol among this group of young smokers, albeit of borderline significance. Roughly half of these smokers smoked fewer than 5 CPD and, given their age, had likely been smoking for fewer years than many of those included in the adult studies, which may account for the weak association of smoking with HDL cholesterol in our study population.

This group of young smokers had a lower total body fat percentage and less leg fat than nonsmokers. Studies in adults typically report lower BMI in smokers and increases in weight and fat with smoking cessation [28-30]. Some studies in adults have suggested that smoking is associated with a pattern of central adiposity, based on higher waist circumferences and lower hip circumferences [28, 29]. Using DXA, a more sensitive measure of fat distribution, 
we observed no significant difference between smokers and nonsmokers in central (trunk) fat but significantly lower leg fat. These observations could reflect a relative preservation of central fat among HIV-positive young smokers. DXA cannot distinguish between intra-abdominal and subcutaneous fat in the trunk region, so we cannot exclude the possibility that smokers and nonsmokers may differ with regard to intraabdominal fat.

Unlike findings reported in adult smokers $[12,13]$, there did not appear to be any difference in glucose tolerance or insulin resistance in these adolescent and young adult smokers, even after adjusting for possible confounders. We also did not find appreciable differences in bone mass between smokers and nonsmokers. As with the lipid findings, it is possible that these youth had not had sufficient exposure to tobacco smoking to adversely affect their glucose and insulin profiles or their bone density.

Taken together, our findings suggest that tobacco smoking has had little to no effect on the metabolic and bone density profiles of these youth. Whether or not this is due to the lower cumulative exposure to tobacco smoke compared with the older smokers reported in the adult studies is uncertain. Clearly longitudinal studies with greater exposure to tobacco are required to examine these parameters over time. However, given the known risks of tobacco smoking and the combined effects of HIV and smoking observed in studies in adults, there are notable implications for secondary prevention of such long-term untoward effects among this young population facing a long life with HIV, its therapies, and associated comorbidities. Our results provide an opportunity to capitalize on the potential longterm benefits that could be achieved by targeting HIVinfected smoking youth with efficacious smoking cessation interventions, early in this window in which there is little evidence that any appreciable harm has already occurred. Offering HIV-infected youth information on the combined risk from smoking and HIV, along with noting the fact that there is still time to make lifestyle changes (i.e., quit smoking) before significant damage is done, may prove a powerful motivator.

Limitations. A potential limitation of our study is that we relied on self-reported smoking status. However, prior data from a similar sample of HIV-positive adolescents showed a high concordance between self-report and cotinine, a biomarker of tobacco exposure [31]. We did not collect data on years from initiation of cigarette smoking and so we cannot make inferences about the duration of smoking on the metabolic profile of HIV-positive tobacco smokers. As such, the apparent lack of effects of tobacco smoking on the metabolic profiles of these participants may reflect a relatively limited exposure to tobacco. It is also possible that some of the differences observed would become more pronounced over time. All clinical sites were located in large urban areas, so these results may not be representative of HIV-infected youth in general. Finally, although we did not have data on actual CPD smoked, but rather a less precise measure of smoking categories (i.e., $\leq 5 \mathrm{CPD}, 6-14 \mathrm{CPD}, 15-24 \mathrm{CPD}, 25-34 \mathrm{CPD}$, and $\geq 35 \mathrm{CPD}$ ), the trends observed from using the smoking categories suggest that there is little dose-response effect from tobacco on these young smokers.

\section{Conclusion}

In summary, there appear to be only minimal effects from tobacco smoking on markers of cardiac risk and bone health in this population of HIV-positive youth. It may be that these HIV-positive smokers had not had sufficient exposure to tobacco to detect significant changes. However, given the long-term risks associated with smoking and the likely compounding effects of HIV and treatments for HIV, it is critical that we find effective targeted interventions to encourage HIV-positive youth smokers to quit smoking before the deleterious effects become apparent.

\section{Conflict of Interests}

All authors reported no conflict of interests.

\section{Acknowledgments}

This work was supported by The Adolescent Medicine Trials Network for HIV/AIDS Interventions (ATN) from the National Institutes of Health (U01 HD 040533 and U01 HD 040474) through the Eunice Kennedy Shriver National Institute of Child Health and Human Development (B. G. Kapogiannis, R. Hazra, and C. Worrell), with supplemental funding from the National Institutes on Drug Abuse (N. Borek) and Mental Health (P. Brouwers, S. Allison). Additional support for this study was provided at four of the participating sites by Grants from the National Center for Research Resources and Clinical and Translational Science Awards, National Institutes of Health, Department of Health and Human Services as follows: Children's National Medical Center, M01RR020359; University of Maryland School of Medicine, M01 RR165001; University of Pennsylvania/Children's Hospital of Philadelphia, NCRRUL1-RR024134; and University of California, San Francisco, UL1 RR024131. The Tulane University Health Sciences Center utilized its Clinical and Translational Research Center (CTRC) for the study; the center was supported in whole or in part by funds provided through the Louisiana Board of Regents RC/EEP (RC/EEP-06). The study was scientifically reviewed by the ATN's Therapeutic Leadership Group. Network, scientific, and logistical support was provided by the ATN Coordinating Center (C. Wilson, C. Partlow) at The University of Alabama in Birmingham. Network operations and analytic support was provided by the ATN Data and Operations Center at Westat (J. Korelitz, B. Driver). The authors acknowledge the contribution of the other ATN 021A and 021B protocol team members (P. Emmanuel, J. Sleasman, C. Worrell, R. Fielding, D. Monte, S. Stoszek, D. S. Hardin, W. A. Meyer III, C. M. Wilson, and N. Liu) and investigators and staff at the following sites that participated and enrolled subjects into this study: Boston Medical Center, Boston, MA; Children's Diagnostic and Treatment Center, Fort Lauderdale, FL; Children's Hospital of Los Angeles, CA; 
Children's Hospital of Philadelphia, PA; Children's Memorial Hospital, Chicago, IL; Children's National Medical Center, Washington, DC; John H. Stroger Jr. Hospital of Cook County and the Ruth M. Rothstein CORE Center, Chicago, IL; Montefiore Medical Center, Bronx, NY; Mount Sinai Medical Center, New York, NY; St. Jude Children's Research Hospital, Memphis, TN; Tulane University Health Sciences Center, New Orleans, LA; University of California at San Francisco, CA; University of California, San Diego, CA; University of Maryland, Baltimore, MD; University of Miami School of Medicine, Miami, FL; University of Puerto Rico, San Juan, PR; and University of South Florida, Tampa, FL; The authors thank Justin Wheeler and Andrea Miller at the Body Composition Analysis Center at Tufts University, who read the DXA scans and tabulated the data. The investigators are particularly indebted to the youth who participated in the ATN 021 studies.

\section{References}

[1] Centers for Disease Control and Prevention (CDC), "Annual smoking-attributable mortality, years of potential life lost, and productivity losses-United States, 1997-2001," Morbidity and Mortality Weekly Report, vol. 54, no. 25, pp. 625-628, 2005.

[2] J. E. Burkhalter, C. M. Springer, R. Chhabra, J. S. Ostroff, and B. D. Rapkin, "Tobacco use and readiness to quit smoking in lowincome HIV-infected persons," Nicotine and Tobacco Research, vol. 7, no. 4, pp. 511-522, 2005.

[3] E. R. Gritz, D. J. Vidrine, A. B. Lazev, B. C. Amick III, and R. C. Arduino, "Smoking behavior in a low-income multiethnic HIV/AIDS population," Nicotine and Tobacco Research, vol. 6, no. 1, pp. 71-77, 2004.

[4] E. M. Mamary, D. Bahrs, and S. Martinez, "Cigarette smoking and the desire to quit among individuals living with HIV," AIDS Patient Care and STDs, vol. 16, no. 1, pp. 39-42, 2002.

[5] M. S. Webb, P. A. Vanable, M. P. Carey, and D. C. Blair, "Cigarette smoking among HIV+ men and women: examining health, substance use, and psychosocial correlates across the smoking spectrum," Journal of Behavioral Medicine, vol. 30, no. 5, pp. 371383, 2007.

[6] "Cigarette smoking among adults-United States, 2006," Morbidity and Mortality Weekly Report, vol. 56, no. 44, pp. 1157-1161, 2007.

[7] C. Lewden, D. Salmon, P. Morlat et al., "Causes of death among human immunodeficiency virus (HIV)-infected adults in the era of potent antiretroviral therapy: Emerging role of hepatitis and cancers, persistent role of AIDS," International Journal of Epidemiology, vol. 34, no. 1, pp. 121-130, 2005.

[8] F. J. Palella Jr., R. K. Baker, A. C. Moorman et al., "Mortality in the highly active antiretroviral therapy era: changing causes of death and disease in the HIV outpatient study," Journal of Acquired Immune Deficiency Syndromes, vol. 43, no. 1, pp. 2734, 2006.

[9] S. Grinspoon and A. Carr, "Cardiovascular risk and body-fat abnormalities in HIV-infected adults," The New England Journal of Medicine, vol. 352, no. 1, pp. 48-62, 2005.

[10] N. L. Benowitz, "Cigarette smoking and cardiovascular disease: pathophysiology and implications for treatment," Progress in Cardiovascular Diseases, vol. 46, no. 1, pp. 91-111, 2003.

[11] P. Frey, D. D. Waters, D. A. Demicco et al., "Impact of smoking on cardiovascular events in patients with coronary disease receiving contemporary medical therapy (from the treating to new targets [TNT] and the incremental decrease in end points through aggressive lipid lowering [IDEAL] trials)," The American Journal of Cardiology, vol. 107, no. 2, pp. 145-150, 2011.

[12] A. C. Frati, F. Iniestra, and C. R. Ariza, "Acute effect of cigarette smoking on glucose tolerance and other cardiovascular risk factors," Diabetes Care, vol. 19, no. 2, pp. 112-118, 1996.

[13] S. Attvall, J. Fowelin, I. Lager, H. von Schenck, and U. Smith, "Smoking induces insulin resistance-a potential link with the insulin resistance syndrome," Journal of Internal Medicine, vol. 233, no. 4, pp. 327-332, 1993.

[14] C. Grunfeld, D. P. Kotler, D. K. Arnett et al., "Contribution of metabolic and anthropometric abnormalities to cardiovascular disease risk factors," Circulation, vol. 118, no. 2, pp. e20-e28, 2008.

[15] H. P. Dimai and M. Chandran, "Official Positions for FRAX clinical regarding smoking from Joint Official Positions Development Conference of the International Society for Clinical Densitometry and International Osteoporosis Foundation on FRAX," Journal of Clinical Densitometry, vol. 14, no. 3, pp. 190193, 2011.

[16] J. A. Womack, J. L. Goulet, C. Gibert et al., "Increased risk of fragility fractures among HIV infected compared to uninfected male veterans," PLoS ONE, vol. 6, no. 2, Article ID e17217, 2011.

[17] J. M. Vogel, J. W. Davis, A. Nomura, R. D. Wasnich, and P. D. Ross, "The effects of smoking on bone mass and the rates of bone loss among elderly Japanese-American men," Journal of Bone and Mineral Research, vol. 12, no. 9, pp. 1495-1501, 1997.

[18] N. H. Bjarnason and C. Christiansen, "The influence of thinness and smoking on bone loss and response to hormone replacement therapy in early postmenopausal women," Journal of Clinical Endocrinology and Metabolism, vol. 85, no. 2, pp. 590596, 2000.

[19] J. Tamaki, M. Iki, Y. Fujita et al., "Impact of smoking on bone mineral density and bone metabolism in elderly men: the Fujiwara-kyo Osteoporosis Risk in Men (FORMEN) study," Osteoporosis International, vol. 22, no. 1, pp. 133-141, 2011.

[20] V. Yoon, N. M. Maalouf, and K. Sakhaee, "The effects of smoking on bone metabolism," Osteoporosis International, vol. 23, no. 8, pp. 2081-2092, 2012.

[21] K. Anastos, D. Lu, Q. Shi et al., "The association of bone mineral density with HIV infection and antiretroviral treatment in women," Antiviral Therapy, vol. 12, no. 7, pp. 1049-1058, 2007.

[22] K. Mulligan, D. R. Harris, P. Emmanuel et al., "Low bone mass in behaviorally HIV-infected young men on antiretroviral therapy: adolescent trials network study 021B," Clinical Infectious Diseases, vol. 55, no. 3, pp. 461-468, 2012.

[23] K. Mulligan, D. R. Harris, D. Monte et al., "Obesity and dyslipidemia in behaviorally HIV-infected young women: adolescent trials network study 021," Clinical Infectious Diseases, vol. 50, no. 1, pp. 106-114, 2010.

[24] K. J. Ellis, R. J. Shypailo, D. S. Hardin et al., "Z score prediction model for assessment of bone mineral content in pediatric diseases," Journal of Bone and Mineral Research, vol. 16, no. 9, pp. 1658-1664, 2001.

[25] W. T. Friedewald, R. I. Levy, and D. S. Fredrickson, "Estimation of the concentration of low-density lipoprotein cholesterol in plasma, without use of the preparative ultracentrifuge," Clinical Chemistry, vol. 18, no. 6, pp. 499-502, 1972.

[26] W. Y. Craig, G. E. Palomaki, and J. E. Haddow, "Cigarette smoking and serum lipid and lipoprotein concentrations: an 
analysis of published data," British Medical Journal, vol. 298, no. 6676, pp. 784-788, 1989.

[27] M. H. Criqui, R. B. Wallace, G. Heiss, M. Mishkel, G. Schonfeld, and G. T. Jones, "Cigarette smoking and plasma high-density lipoprotein cholesterol. The Lipid Research Clinics Program Prevalence Study." Circulation, vol. 62, no. 4, pp. IV70-IV76, 1980.

[28] D. Canoy, N. Wareham, R. Luben et al., "Cigarette smoking and fat distribution in 21,828 british men and women: a populationbased study," Obesity Research, vol. 13, no. 8, pp. 1466-1475, 2005.

[29] M. Akbartabartoori, M. E. J. Lean, and C. R. Hankey, "Relationships between cigarette smoking, body size and body shape," International Journal of Obesity, vol. 29, no. 2, pp. 236-243, 2005.

[30] A. Kleppinger, M. D. Litt, A. M. Kenny, and C. A. Oncken, "Effects of smoking cessation on body composition in postmenopausal women," Journal of Women's Health, vol. 19, no. 9, pp. 1651-1657, 2010.

[31] S. L. Nichols, A. Lowe, X. Zhang et al., "Concordance between self-reported substance use and toxicology among HIV-infected and uninfected at risk youth," Drug and Alcohol Dependence, vol. 134, pp. 376-382, 2014. 


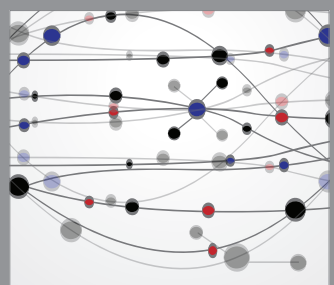

The Scientific World Journal
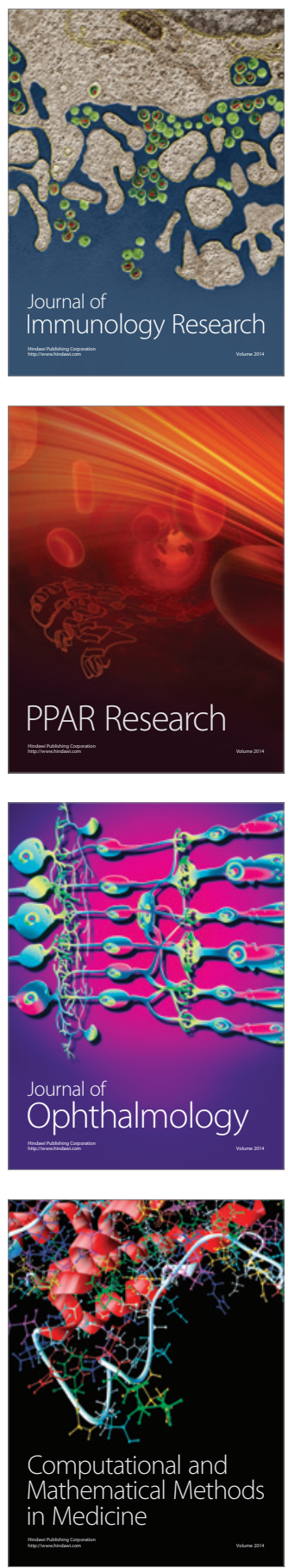

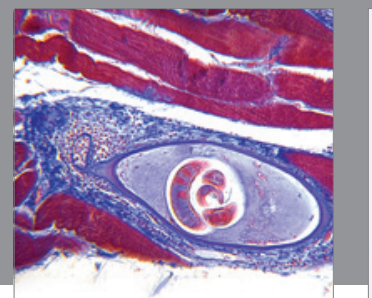

Gastroenterology

Research and Practice
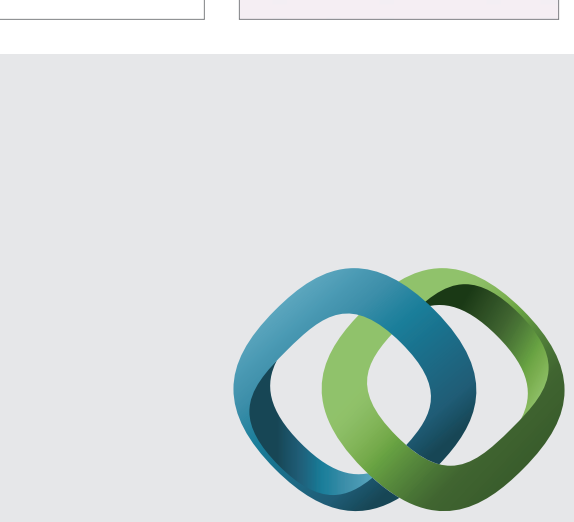

\section{Hindawi}

Submit your manuscripts at

http://www.hindawi.com
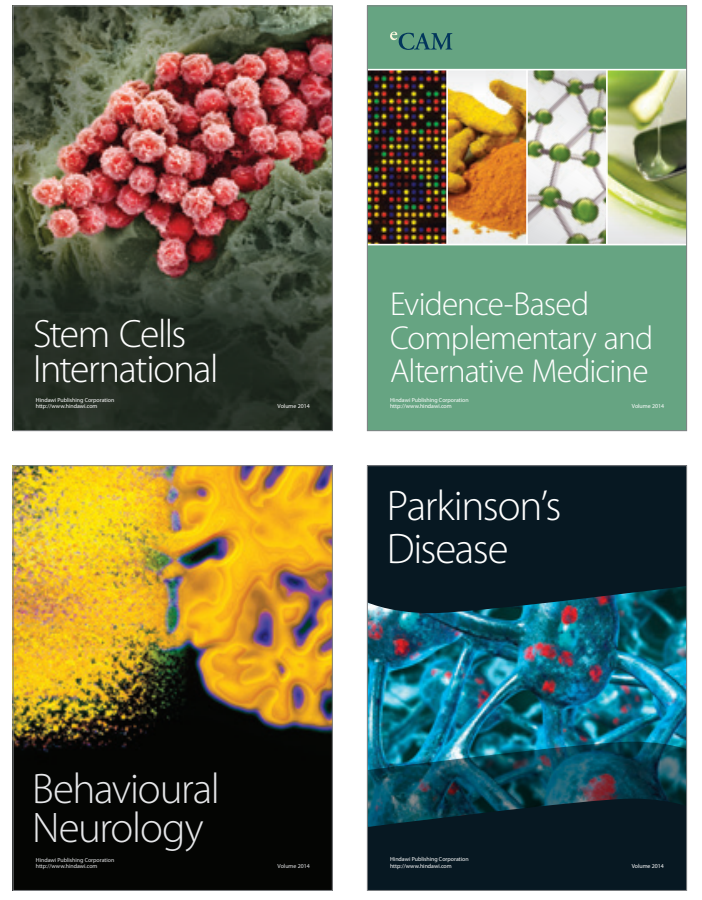
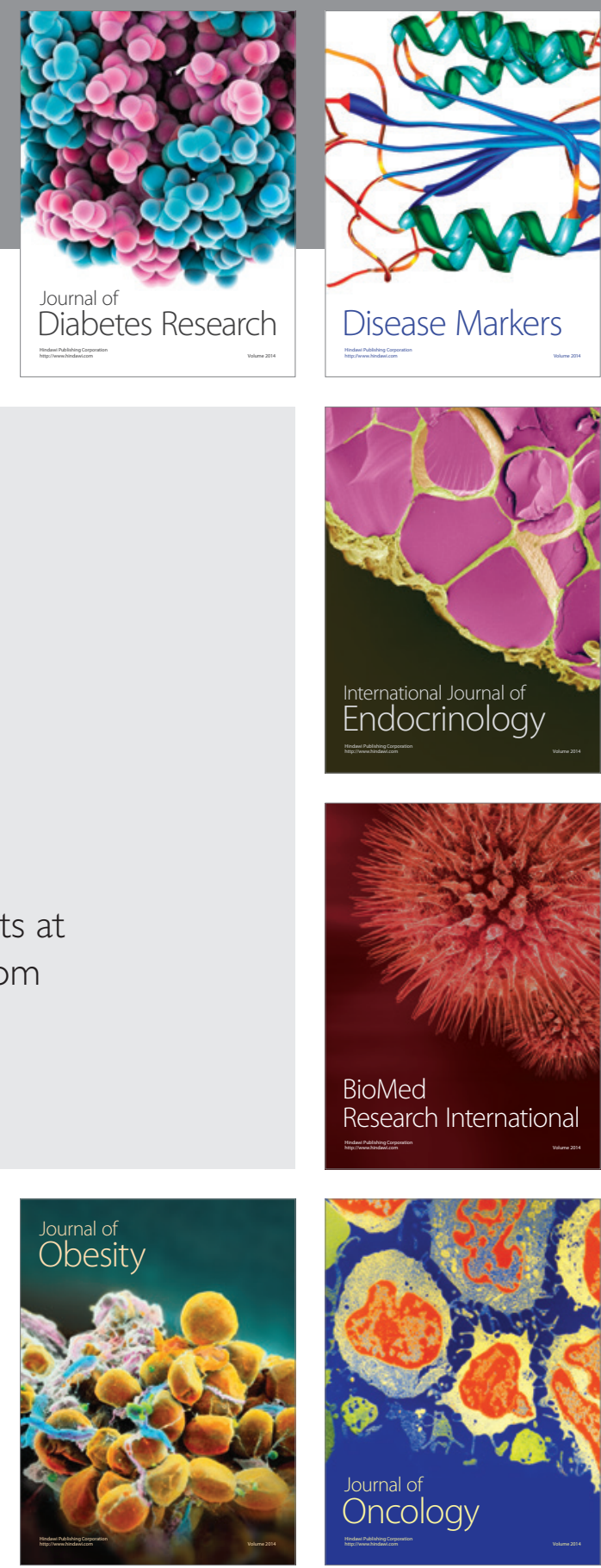

Disease Markers
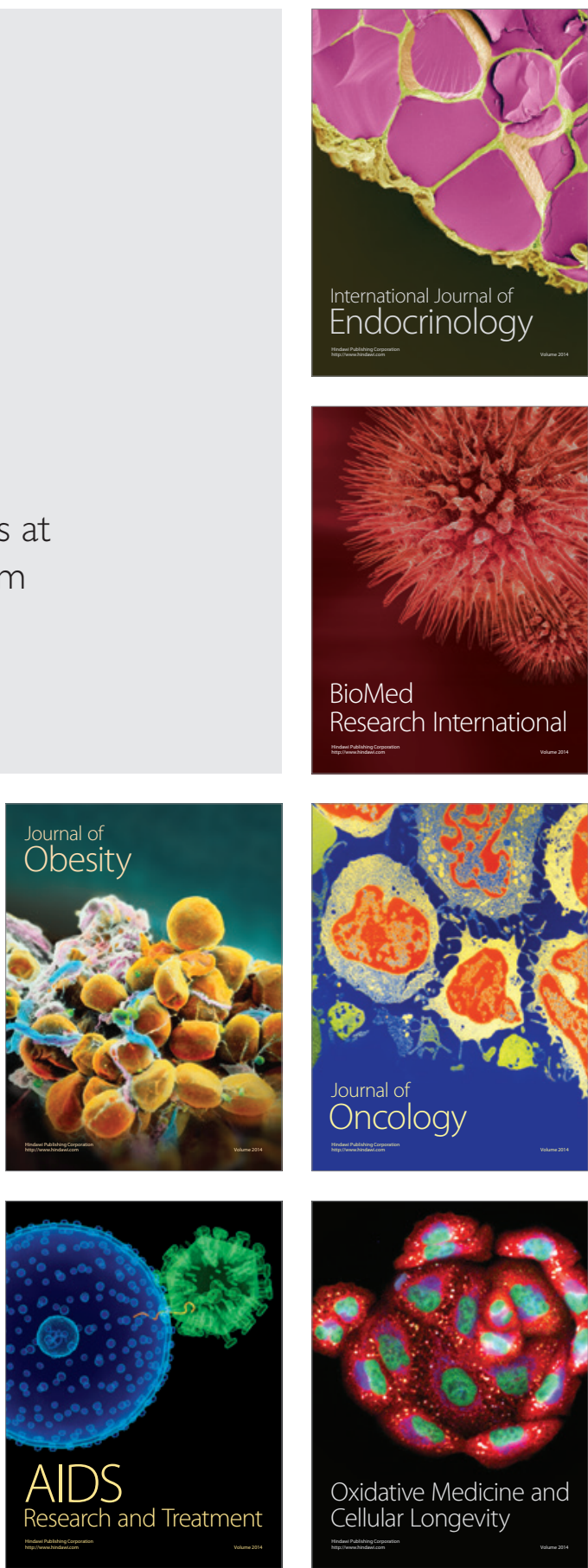